\title{
HOMESCHOOLING: A FUNCIONALIDADE DO ENSINO DOMICILIAR E A ANTIJURIDICIDADE PERANTE O ORDENAMENTO JURÍDICO BRASILEIRO
}

\author{
André Felipe Vilanova Costa ${ }^{1}$ \\ Meiriele de Sousa Medeiros ${ }^{2}$ \\ ${ }^{1}$ Faculdade do Vale do Itapecuru (FAI), Caxias, MA, Brasil. \\ ${ }^{2}$ Faculdade do Vale do Itapecuru (FAl), Caxias, MA, Brasil. ${ }^{2}$
}

Resumo: Este artigo trata sobre o homeschooling e o seu reconhecimento como uma opção de aplicação da educação, por parte da família, em seguir uma modalidade diferente da que é presenciada nas escolas, abordando o referido método como uma forma de obter diante das crianças um ensino que possibilite aos pais acompanharem mais de perto os passos de seus filhos perante o desenvolvimento do mundo atual. Procura-se analisar a real função desse instituto para aplicação de uma educação de qualidade e que é voltada para as particularidades de cada criança em obter um ensino de qualidade e a vivência do ambiente familiar, com as suas características e vivências. O estudo foi desenvolvido com base na bibliografia especializada sobre o tema, bem como obras de Barbosa (2013), Andrade (2014) e Clark (2016); e na observação da normatização em vigor e os projetos de leis pertinentes a regularização desse instituto em nosso ordenamento jurídico. Utilizou-se o método comparativo para a conclusão dos elementos legislativos. E o método de história de vida com a função de compreender os motivos que levaram a Família Cunha a aplicar a educação domiciliar com os filhos. Dessa forma, tendo como fundamento a Constituição Federal, busca-se analisar os motivos pelos quais este modelo educacional não possui estandardização, uma vez que no Poder Judiciário brasileiro existem Projetos de Leis e lides de famílias que aplicam o ensino domiciliar e se sentem coagidas a continuar ou não com esse processo.

Palavras-chave: Homeschooling. Projetos de lei. Educação.

\begin{abstract}
This article its about homeschooling and its recognition as an option of applying the education of the family to follow a different modality than that seen in schools, approaching this method as a way to obtain before the children an education that allows parents to monitor more closely the steps of their children in the face of the development of today's world. The aim is to analyse the real function of this institute for the application of a quality education and which is focused on the particularities of each child in obtaining a quality education and the experience of the family environment, with its characteristics and experiences. The study was developed based on the specialized literature on the topic, as well as works by Barbosa (2013), Andrade (2014) and Clark (2016); and in the observation of the normatization in force and the pertinent legislative bill the regularization of this institute in our legal system. The comparative method has been used to finalise the legislative elements. And the method of life history with the function of understanding the reasons that led the Cunha Family to apply home education with their children. Thus, based on the Federal Constitution, it seeks to analyze the reasons why this educational model does not have standardization, since in the Brazilian Judiciary there are legislative bill and dispute for families who apply home education and feel coerced to continue or not with this process.
\end{abstract}

Keywords: Homeschooling. Legislative bill. Education.

Como citar: COSTA, A. F. V.; MEDEIROS, M. S. Homeschooling: a funcionalidade do ensino domiciliar e a antijuridicidade perante o ordenamento jurídico brasileiro. Revista Científica Novas Configurações - Diálogos Plurais, Luziânia, v. 1, n.1, p. 34-45, 2020. https://doi.org/.10.4322/2675-4177.2020.005

Apoio financeiro: Nenhum.

Conflitos de interesses: Os autores declaram não haver nenhum conflito de interesse.

Correspondência: andrevilanova_@hotmail.com

Recebido: 18 Abr 2020

Aprovado: 18 Mai 2020

Editor: Marcelo Máximo Purificação.

Este é um artigo publicado em acesso aberto (Open Access) sob a licença Creative Commons Attribution, que permite uso, distribuição e reprodução em qualquer meio, sem restrições desde que o trabalho original seja corretamente citado. 


\section{INTRODUÇÃO}

O trabalho, ora apresentado, possui como finalidade demonstrar a real importância do homeschooling e a vivência que as famílias praticantes possuem para que seja de conhecimento a toda sociedade; averiguando tal modelo educacional, demonstrando as suas origens, aplicações, como o Poder Judiciário se comporta diante desse instituto e a opinião das próprias famílias. Além do que, é necessário demonstrar a eficácia que esse modelo possui e é apontado com bons olhos visto que a educação brasileira vem em uma decrescente, tornando-se um pesadelo para as famílias que acompanham os passos de seus filhos perante o mundo que se desenvolve e tem a abrangência de múltiplas ideologias que vão contra o que os pais almejam para os seus descendentes.

Em suma, o procedimento de avalição busca ser claro e objetivo, em razão de prover as necessidades que o trabalho aspira: que é divulgar para os leitores a importância que os pais possuem e o direito-dever em escolher o gênero de instrução que será adotado para os seus filhos. Assim, mostra as dificuldades que as famílias obtêm de não ter em nosso ordenamento jurídico uma legalidade que alcance a instrução desse instituto educacional, apesar de não ser proibido no Brasil.

O presente estudo se delimita ao Brasil, por ser um país que ainda não possui uma normatização para o homeschooling e em virtude de exteriorizar o crescimento que o ensino domiciliar vem tendo no país. Com isso, há inúmeras lides em trâmites e, por consequência, amedrontam os pais, que aplicam este modelo ou buscam aplicar com a sua família, a serem coagidos como "contra as leis" e serem até ameaçados em perder a guarda dos filhos.

Contudo, uma das abrangências ao longo do trabalho se dá em relação a socialização e a importância que se confere aos pais e seus filhos e como se comportam quando o assunto confere ao ato de socializar. É essencial ter em mente que cada criança possui uma necessidade que compete ao seu modo de aprendizagem.

A escolha do tema deu-se com o intuito de analisar o ensino domiciliar de forma ampla e direta como maneira de demonstrar a sua funcionalidade para auxiliar as pessoas que desconhecem. Por isso, investiga a opinião de educadores que estudam o homeschooling e a sua real função, além dos problemas a serem levantados através da pesquisa de campo. Diante desse contexto, questiona-se por quais motivos a prática do homeschooling não é autorizada em nosso ordenamento jurídico?

O estudo processou-se por meio de revisão bibliográfica como Barbosa (2013), Andrade (2014) e Clark (2016); trabalhos científicos, análises de leis, pesquisa de campo e de entrevista em formato de questionário. Utilizou-se o método comparativo para a dedução dos elementos que se fazem presente no tema em questão. Para a explicação jurídica desse tema, se faz necessário a utilização do método em comento com o objetivo de entender a normatização das leis e sua adequação perante a sociedade. Sendo imprescindível no ramo desta investigação, utilizou-se o método de história de vida diante de um questionário, semiestruturado com perguntas diferentes, sendo todas abertas e diretas; aplicado a uma família, composta por: Sr. Cleylton Paixão da Cunha, Sra. Daniele Dandara Mota Teixeira Cunha e seus quatro filhos, sendo três meninas e um menino, que possuem idades que variam entre 7 (sete) meses a 6 (seis) anos de idade e são identificados pelas iniciais de seus respectivos nomes. A finalidade é que os pais pudessem se manifestar sobre o tema, quais motivos levaram a família para aplicação desse modelo educacional e de que forma eles aplicam o homeschooling com os seus filhos, além de mostrar as dificuldades e êxitos diante desse método de ensino.

$\mathrm{O}$ presente artigo encontra-se organizado em 3 (três) seções: a primeira aborda a origem do homeschooling, dando ênfase a sua estrutura dentro do Brasil, a segunda seção aduz sobre as aplicações do homeschooling em nosso ordenamento jurídico e a terceira seção apresenta a análise acerca da socialização interpelando falas da família entrevistada com a de educadores. Com a presente pesquisa, pode-se atenuar o relevante papel da educação e a relevância desse instituto para toda a sociedade, pois a Carta Magna assegura que todos têm direito à educação e este é um dever do Estado e da Família.

\section{ORIGEM DO HOMESCHOOLING: CRISE EDUCACIONAL}

O termo usual homeschooling tem sua origem nos Estados Unidos da América (EUA) em que consiste uma modalidade de ensino que os pais utilizam como uma possibilidade de poderem educar os filhos no ambiente doméstico, não possuindo uma padronização escolar no aprendizado de seus pupilos e que estes tenham uma busca constante do aprendizado em torno da família. Sendo um termo norteamericano, a palavra homeschooling padronizou-se de maneira internacional para representar a caracterização deste modelo educacional e que até nos dias atuais tem mantido um constante crescimento nas famílias que aderem esta modalidade. 
Aqui no Brasil, o termo homeschooling não possui uma tradução exata e padronizada de maneira a ser utilizada de forma similar por parte das famílias, educadores, jurídicos especializados na área e até mesmo pelos autores. Na tradução literal de homeschooling, temos a junção das palavras home (casa) com a palavra school (escola), sendo este último utilizado no gerúndio (schooling). Com esta tradução, dispomos para o português o emprego de Educação Domiciliar. No entanto, "são encontradas diferentes traduções para o termo homeschooling, denominado como "ensino em casa", "ensino doméstico", "educação doméstica" ou ainda "educação domiciliar", tanto pela literatura, quanto pelos documentos legais que tratam do tema" (BARBOSA, 2013, p. 18). Com estes termos apresentado, o presente artigo não pretende utilizar apenas um termo, sendo todos eles relevantes para a pesquisa aqui apresentada.

Com as nomenclaturas apresentadas, se faz necessário colocarmos o caráter histórico do surgimento do homeschooling, ou seja, em que contexto na época está atrelado o seu surgimento perante a sociedade norte-americana. O precursor do termo homeschooling utilizava o vocábulo "Unschooling ${ }^{1}$, ou desescolarização, termo cunhado originalmente pelo escritor americano John Holt em seu livro Teach Your Own (1981), para se referir ao processo inicial que culminará na homeschooling" (ANDRADE, 2014, p. 19). O uso deste termo dava-se ao fato de uma crise na educação americana perante a Revolução Sexual, que teve início nos anos de 1960, um ponto crucial para se buscar a reforma na educação.

Segundo retrata a autora Mary Kay Clark:

Nas décadas de 1960 e 1970, os pais católicos começaram a praticar o homeschooling porque acreditavam ser esse o único modo de protegerem seus filhos. Eles estudaram as Escrituras e os ensinamentos da Igreja para determinar se o homeschooling era permitido. Ora, não apenas as escrituras e a Igreja apoiam o homeschooling, como em diversas situações chegam a recomendá-lo. (CLARK, 2016, p. 97).

Diante disso, podemos observar que os pais estavam preocupados de "que forma?" e "sobre o que?" os seus filhos estavam aprendendo nas escolas norte-americanas. Com a chegada da Revolução Sexual, tendo presente a eclosão da pílula anticoncepcional e do desenvolvimento dos movimentos feministas e de direitos civis nos EUA, surge uma nova forma de viver e encarar a vida de uma maneira mais erotizada. À vista disso, as escolas passaram a ser um ponto de entrada para estes movimentos e o surgimento de ideologias que buscavam e ainda buscam colocar a família de lado, sendo as salas de aula uma porta de aprendizado para as crianças.

Com esta "falsa liberdade" desencadeada nos anos de 1960, é que no final desta década surgem diversas crises na educação americana com variados problemas enfrentados pelos diretores e pelos próprios pais, e porque não pelas próprias crianças que descobriam um novo mundo baseado na exploração da sexualidade humana (na arte, no cinema e nas músicas). Por conseguinte, surge através de John Holt no final dos anos de 1970 a "desescolarização", que significaria um processo inicial que, posteriormente, culminaria no homeschooling.

No Brasil, a Educação Domiciliar data o seu surgimento no começo dos anos de 1990 e que as famílias que aqui praticavam eram de origem estrangeira, sendo pouquíssima aquelas que adotavam este modelo educacional. Sendo assim, o número de famílias que adotam o ensino domiciliar não possui uma exatidão. Além disso, verificar os seus precursores consiste em mencionar o surgimento do Homeschooling no âmbito do poder judiciário brasileiro. Isso consiste no caso da família Vilhena Coelho, em Anápolis/GO, sendo “[...] a primeira que levou a ação ao Poder Judiciário sobre o tema, recebendo parecer da Câmara de Educação Básica do Conselho Nacional de Educação, manifestação do Ministério Público Federal e julgamento no Superior Tribunal de Justiça" (BARBOSA, 2013, p. 31), provocando uma certa curiosidade sobre o tema e falta de juridicidade em determinar a autorização da Educação Domiciliar em solo brasileiro. Com isso, continua a referida autora:

\footnotetext{
O caso da família Vilhena Coelho/GO ficou conhecido como o primeiro a introduzir o tema no Brasil, após a $\mathrm{CF} / 88$. Como os pais eram pessoas ligadas à área jurídica e por terem iniciado o processo buscando reconhecimento legal do ensino em casa, a trajetória do caso revelou um percurso rico em informações e debates jurídicos, que possibilitaram não somente a emergência do aprofundamento da interpretação dos dispositivos constitucionais e legais relacionados à educação, como se tornou referência sobre o tema. (BARBOSA, 2013, p. 51-52).
}

Assim, afirma o advogado e educador Édison Prado de Andrade, em sua tese de doutorado em Educação, que: 
No Brasil a prática não é autorizada, mas também não é proibida em lei, o que nos leva a discutir nesta tese a antijuridicidade dos pronunciamentos nos tribunais brasileiros no sentido de responsabilização civil e criminal dos pais que a adotam. (ANDRADE, 2014, p. 8).

Através destas palavras, surgem questões importantes e que se perpetuam em nosso país, tanto para os pais quanto para os filhos: Como ajudar os pais que querem aplicar o homeschooling para os seus filhos? Como fazer que esta prática seja direito dos pais? Como ajudar as crianças que sofrem violências, preconceitos e bullying ${ }^{2}$ nas escolas?

Para ajudarem nestas questões, surge no ano de 2010 a Associação Nacional de Educação Domiciliar (ANED), tratando-se de uma instituição sem fins lucrativos e de iniciativa de um grupo de famílias. Dessa maneira, demonstra que "a principal causa defendida pela ANED, é a autonomia educacional da família". E continua dizendo que "assim como os pais têm o dever de educar, têm também o direito de fazer a opção pela modalidade de educação dos filhos"3.

Logo, a Declaração Universal dos Direitos Humanos, dispõe em seu artigo 26 que:

\begin{abstract}
Artigo XXVI
1. Toda pessoa tem direito à instrução. A instrução será gratuita, pelo menos nos graus elementares e fundamentais. A instrução elementar será obrigatória. A instrução técnico profissional será acessível a todos, bem como a instrução superior, está baseada no mérito.

2. A instrução será orientada no sentido do pleno desenvolvimento da personalidade humana e do fortalecimento do respeito pelos direitos humanos e pelas liberdades fundamentais. A instrução promoverá a compreensão, a tolerância e a amizade entre todas as nações e grupos raciais ou religiosos, e coadjuvará as atividades das Nações Unidas em prol da manutenção da paz.

3. Os pais têm prioridade de direito na escolha do gênero de instrução que será ministrada a seus filhos. (BRASIL, Declaração Universal dos Direitos Humanos, 1948).
\end{abstract}

Compreende-se que os pais sempre se preocuparam com a educação de seus filhos e eles sempre foram os seus primeiros educadores. Porém, nos dias atuais com as ideologias presentes na sociedade e em políticas governamentais, faz com que a família através do ensino doméstico tenha uma saída de poder educar os seus pupilos de forma correta e eficaz a que os pais tendem para eles. Assim sendo, é necessário que haja uma normatização que abranja a escolha dos pais e proteja de perseguições governamentais, como ocorre em países como a Suécia e Alemanha (que a prática do homeschooling é proibida). Conforme a Declaração Gravissimun Educationis (1965), sobre a Educação Cristã: “A família é, portanto, a primeira escola das virtudes sociais de que as sociedades têm necessidade".

\title{
3 A ATUAL APLICAÇÃO JURÍDICA BRASILEIRA EM FACE DO HOMESCHOOLING
}

No atual ordenamento jurídico brasileiro não possuímos a caracterização legal para a prática do homeschooling, porém não existe uma proibição em lei que descaracteriza a prática desta modalidade educacional a qual os pais escolhem para os seus filhos. No entanto, muitas famílias que põe em prática a Educação Domiciliar escolhem serem discretos ao falarem sobre a modalidade escolhida e a não ida dos filhos para as escolas. Já outras famílias, utilizam em suas redes sociais a divulgação do homeschooling como uma maneira de mostrar esse modelo educacional e expor a população que não conhece as suas características, sem nenhum tipo de receio por parte dos próprios vizinhos e também por parte do Estado, em serem denunciados e levados ao poder judiciário. Assim, caracteriza Aguiar em suas lições que:

O ensino domiciliar, como substituto do ensino escolar, não é proibido expressamente por nenhuma norma no ordenamento jurídico brasileiro, seja constitucional, legal ou regulamentar. Nem, tampouco, é expressamente permitido ou regulado por qualquer norma. O fundamento dessa omissão é bastante simples: o assunto somente está sendo debatido no Brasil recentemente e, ainda, de forma tímida. (AGUIAR apud ALEXANDRE, 2016, p. 10).

No que se refere ao Brasil, há um histórico de projetos de lei que visam regulamentar a educação domiciliar, são eles: em 2001 o Projeto de Lei no 6.001 do Deputado Federal Ricardo Izar (PTB/SP); em 2002 o Projeto de Lei n 6.484 do Deputado Federal Osório Adriano (PFL/DF); em 2008 o Projeto de Lei $\mathrm{n}^{\circ} 3.518$ dos Deputados Federais Henrique Afonso (PT/AC) e Miguel Martini (PHS/MG) e o Projeto de

\footnotetext{
2 De origem inglesa e sem tradução no Brasil, é empregado para expressar comportamentos agressivos no ambiente escolar, praticados pelo educando. Os atos ocorrem de maneira intencional e repetitiva contra um ou mais indivíduos, que se encontram impossibilitados de reagir às agressões sofridas. (MARTINEZ, 2011, p.10)

${ }^{3}$ Fonte: https://www.aned.org.br/sobre-nos/quem-somos-aned (Acesso em 12/09/19 às 17h37min).
} 
Lei n 4.122 do Deputado Federal Walter Brito Neto (PRB/PB). Todas estas propostas legislativas tendentes a regulamentar o ensino domiciliar foram arquivadas pela Comissão de Educação e Cultura. Já no ano de 2012 surge o Projeto de Lei no 3.179 do Deputado Federal Lincoln Portela (PR/MG) e que está em trâmite processual perante as casas legislativas, tendo sua última movimentação em 02/10/19 por meio da Deputada Caroline de Toni (PSL/SC) ${ }^{4}$. Atualmente, temos o Projeto de Lei no 2.401/19 apresentado pelo governo em exercício e que "dispõe sobre o exercício do direito à educação domiciliar, altera a Lei $\mathrm{n}^{\circ}$ 8.069, de 13 de julho de 1990 - Estatuto da Criança e do Adolescente, e a Lei no 9.394, de 20 de dezembro de 1996, que estabelece as diretrizes e bases da educação nacional"5.

Diante de todas estas propostas, observamos que há uma urgência e necessidade do estabelecimento do Ensino Domiciliar para as famílias brasileiras, visto que já é uma prática consolidada em diversos países europeus e principalmente nos Estados Unidos. Como diz a ministra da Mulher, da Família e dos Direitos Humanos, a Sra. Damares Alves: "é uma questão de estar no mesmo pé de igualdade dos países já desenvolvidos que já praticam o ensino domiciliar” (2019)

A seguir, veremos o que diz as legislações no ordenamento jurídico brasileiro e quanto as possibilidades da atual disciplina jurídica educacional brasileira quanto a prática do homeschooling.

A Constituição Federal de 1988 (CF/88) dispõe artigos que são fundamentais para a aplicação da educação em âmbito nacional e contêm dispositivos importantíssimos para que os filhos tenham uma educação digna e que os pais cumpram conforme está disposto em nossa Carta Magna. $\mathrm{O}$ art. $6^{\circ}$ da $\mathrm{CF} / 88$ enumera como direitos sociais "a educação, a saúde, a alimentação, o trabalho, a moradia, o transporte, o lazer, a segurança, a previdência social, a proteção à maternidade e à infância, a assistência aos desamparados, na forma desta Constituição" (BRASIL, 1988). Em vista disso, a educação surge como uma das principais garantias fundamentais para a sociedade brasileira e traz para os pais e o Estado, como instituições, um dever árduo e requer que as crianças sejam formadas por meio de um modelo educacional digno e eficaz para a obtenção de seu próprio crescimento e produza frutos.

Continua a nossa Carta Magna em seu artigo 205:

Art. 205. A educação, direito de todos e dever do Estado e da família, será promovida e incentivada com a colaboração da sociedade, visando ao pleno desenvolvimento da pessoa, seu preparo para o exercício da cidadania e sua qualificação para o trabalho. (BRASIL, Constituição Federal, 1988).

Através deste artigo constitucional, tanto a Família quanto o Estado são responsáveis em garantir a educação para com as crianças. E dessa forma, é necessário que se cumpra todo um processo educativo de completa responsabilidade perante o ordenamento e exige de todos um aprofundamento necessário que vise assimilar os conhecimentos específicos e passá-lo adiante.

Além da $\mathrm{CF} / 88$, encontramos em nosso bojo as leis infraconstitucionais que são ulteriores a Constituição, destacam-se: a lei 8.069/90 ECA (Estatuto da Criança e do Adolescente) e a lei 9.394/96 LDB (Lei de Diretrizes e Bases da Educação Nacional). Conforme afirma ALEXANDRE (2016, p. 10) estas duas leis em nosso ordenamento jurídico "reafirmaram os princípios da gratuidade, obrigatoriedade, responsabilidade do poder público e o ensino fundamental como direito público subjetivo".

Todavia, é comum considerarmos que estas leis supramencionadas caracteriza o Estado como o principal modelo educacional existente, pois é nele que encontramos os moldes para que haja controle de frequência escolar e que é a escola o principal lugar de socialização para as crianças. Logo, o art. 24 da LDB menciona sobre a educação básica e suas regras e o art. 31 da LDB sobre a educação infantil afirmam que:

Art. 24. A educação básica, nos níveis fundamental e médio, será organizada de acordo com as seguintes regras comuns:

VI - o controle de frequência fica a cargo da escola, conforme o disposto no seu regimento e nas normas do respectivo sistema de ensino, exigida a frequência mínima de setenta e cinco por cento do total de horas letivas para aprovação;

Art. 31. A educação infantil será organizada de acordo com as seguintes regras comuns:

IV - controle de frequência pela instituição de educação pré-escolar, exigida a frequência mínima de $60 \%$ (sessenta por cento) do total de horas; (BRASIL, Lei de Diretrizes e Bases da Educação Nacional, 1996)

\footnotetext{
${ }^{4}$ Fonte:https://www.camara.leg.br/proposicoesWeb/fichadetramitacao?idProposicao=534328 (Acesso em 08/10/19 às 10h35min). ${ }^{5}$ Fonte:https://www.camara.leg.br/proposicoesWeb/fichadetramitacao?idProposicao=2198615 (Acesso em 08/10/19 às 10h55min). ${ }^{6}$ Fonte:https://www.gazetadopovo.com.br/educacao/homeschooling-deve-ser-aprovado-no-brasil-ate-novembro-diz-damares/ (Acesso em 08/10/19 às $11 \mathrm{~h} 33 \mathrm{~min}$ ).
} 
Mediante estes dois artigos apresentados da LDB, não podemos realizar uma espécie de análise rasa e direta, mas é de suma importância que entendamos o modelo buscado pelo Estado na busca de educar o cidadão e os direitos que são pertinentes a eles. É assim que caímos no erro de sermos exegetas de nós mesmo e aplicamos nossas próprias referências sem analisar o caso e que vivenciamos no mundo atual. Nisto, o ministro do STJ (Superior Tribunal de Justiça) Domingos Franciulli Netto (in memoriam), corrobora o fato de que o processo que se enfatiza a LDB corresponde ao uma educação tradicional e de controle das escolas, pontuando que:

Como é de ver, em harmonia com as disposições constitucionais, a lei federal busca defender o direito à educação de todo o cidadão, mas ressalva a liberdade de aprender. Com esse desejo, então, passa a regular a qualidade do ensino que será oferecido nas escolas, fixando, por exemplo, os objetivos do ensino fundamental (art. 32).

Conclui-se, portanto, que a regulamentação específica, sobretudo no que tange à carga horária de cada curso e jornada diária em sala de aula, diz respeito apenas à educação tradicional, que, entretanto, segundo se depreende pela análise sistemática do diploma em questão, não é a única forma de aprendizado. (FRANCIULLI NETTO, 2005, p. 8 -9)

Conforme disposto e analisando diferentes casos, é possível enxergar que há entendimentos do Ministério Público acerca do ensino doméstico presente entre as famílias que a praticam. Nisto, estes entendimentos não são únicos, ou seja, possui posicionamentos diversos em prol do ensino domiciliar ou indeferimento do Ministério Público para a não aplicação deste método educacional que se dá em casa sob o seio familiar. Desta maneira, acentua Barbosa (2013, p. 72) em suas pesquisas com famílias que praticavam o homeschooling (conforme a data de seus estudos) e análise de suas batalhas judiciais perante o ordenamento da época, evidencia o caso da família Silva/PR que, deste modo, "destaca-se dos demais por seu o único do país que, até o momento, recebeu autorização da Justiça local para dar continuidade ao ensino dos filhos em casa, sendo acompanhados pela Promotoria e pela Justiça [...]".

Como se vê, muitas famílias ainda sofrem com as mesmas dificuldades de levar o ensino domiciliar adiante e em julgamento recente (setembro de 2018) o STF (Supremo Tribunal Federal) determinou que o homeschooling não poderia ser admitido enquanto não houvesse uma lei que normatize este modelo educacional. Através desta definição do STF, observou que não houve declaração de inconstitucionalidade do ensino por parte do Supremo e nem proibição para os pais quanto a prática, mas que haja uma criação de lei que legalize e disponha sobre o homeschooling. Assim, todos os processos em razão das famílias que praticam ensino domiciliar estão suspensos, ou seja, foi determinado pelo STF o seu sobrestamento. Como já dito anteriormente, o Projeto de Lei 2.401/19, proposta do governo atual está em tramitação em comissão especial da Câmara dos Deputados.

Cabe ressaltar, que presenciamos um ambiente múltiplo de etnias, ideologias, opção sexual e até opção educacional. Neste emaranhado de ideias, os pais e os seus filhos são alvos de resistência naquilo que acham capacitados de passar a seus descendentes. Afirma Andrade (2014, p. 101) que "além dos argumentos teóricos, existem os fatos por meio dos quais os pais percebem que, por um lado, o sistema escolar é precário [...], o modelo de educação domiciliar é mais eficaz com vistas ao alcance da assimilação destes conhecimentos". É nesse contexto social, que encontramos o homeschooling como um modelo eficaz para proteger as crianças de serem imersas a uma geração bastante além de seu tempo e que a cada fracasso, é um sinal de reprovação por parte da sociedade.

\section{SOCIALIZAÇÃO: COMO OS PAIS SE PORTAM DIANTE DESSE FATOR PRIMORDIAL PARA AS CRIANÇAS?}

A socialização é sem dúvidas um papel fundamental para a vida de todos aqueles que habitam e convivem diariamente com um sortido número de pessoas, em seus variados estilos de vida e opiniões. Nisso, consiste uma das maiores preocupações entre educadores, cientistas e dos próprios pais em relação de como as crianças se comportam frente a todos esses acontecimentos.

Baseado nesse contexto, essa seção busca analisar sobre a socialização e sobre um questionário aplicado perante a família Cunha que pratica o homeschooling, em Caxias-MA, com os seus filhos. A família que se propôs a ajudar na pesquisa, é composta pelo Sr. Cleylton Paixão da Cunha e pela Sra. Daniele Dandara Mota Teixeira Cunha, e ambos são pais de quatro filhos: 3 (três) meninas: M.S.T.C. - 6 anos e 5 meses, A.L.T.C. -4 anos e 9 meses, I.T.C. -2 anos e 4 meses; e 1 (um) menino: B.T.C. - 7 meses. Devido as poucas idades das crianças, atualmente, a prática do homeschooling ocorre com as duas filhas mais velhas: a de seis anos e cinco meses e de quatro anos e nove meses. A primeira filha está na 
alfabetização e a segunda filha está na pré-alfabetização (documento anexo encontra-se no Apêndice "D" deste artigo científico).

O presente trabalho pretende analisar a realidade da família e as circunstâncias que envolve o modelo educacional que os pais desenvolvem e suas dificuldades no dia a dia e os aprendizados para com os seus filhos. Logo, umas das perguntas presente no questionário menciona de que modo à família responde as críticas por parte da sociedade quanto à falta de socialização proporcionada pelo ensino em casa e o que fazem para contornar a questão.

Nas lições de Barbosa, a autora faz o seguinte questionamento sobre a socialização e a modalidade de ensino investigada, que consiste:

[...] a relevância dada à questão da socialização na formação das crianças e adolescentes é evidenciada por todo o debate que envolve o ensino em casa vs escola. Tal tema mostra-se recorrente entre os defensores do ensino em casa e seus críticos e revelou-se presente nos casos analisados das famílias brasileiras, nas decisões da Justiça (como apresentado no primeiro capítulo), nos PLs que foram apresentados visando à normatização dessa modalidade de ensino no país, além das reportagens divulgadas pela imprensa que, de forma crescente, vêm expondo o tema do ensino em casa para a população. (BARBOSA, 2013, p.236).

Dessa maneira, a socialização é um tema bastante abordado por todos aqueles presentes no campo da educação e seu desenvolvimento no processo escolar. Com isso, esse tema surge como um fator determinante para os educadores que vão contra a prática do homeschooling nos lares familiares. Assim, defendem que a escola é o principal meio presente na sociedade atual como o meio mais eficaz e próspero paras as crianças se socializar e buscar conhecer pessoas com outras vivências de vida. Destaca Rocha que:

Na escola a criança encontra o professor e os saberes. Qual o simbolismo deles? A ocupação do professor é das mais singulares. Sua raiz é o fato trivial que a condição humana exige o provimento de cuidados de crescimento e de aprendizagens por um longo período. Sem nossos aprendizados juntos à geração que nos trouxe ao mundo, somos nada; [...] (ROCHA, 2017, p. 118).

É inegável que as escolas são locais abertos e necessários para a socialização e por conseguinte um lugar que as crianças se sentem confortáveis em explorar novos conhecimentos e amizades. É relevante apresentar que foi por meio das escolas onde surgiram grandes autores, doutores, artistas e educadores; e são, no mundo atual, pessoas renomadas para o surgimento de ideias e pensamentos úteis para a geração contemporânea. Tudo isso teve ênfase na Constituição Federal de 1934 onde "a Educação foi declarada como um direito social, gratuito e obrigatório em nosso país" (ANDRADE, 2014, p. 253).

Continua Andrade, que a educação obrigatória através das escolas surge no período dos anos de 1920 como uma maneira eficaz de alavancar a história brasileira com o objetivo de positivar a ação social de educadores e intelectuais presentes na época e de transformar a escolarização como um instrumento de correção do processo evolutivo para a sociedade brasileira, assim:

O desenvolvimento da educação de massa no Brasil, da educação escolar obrigatória e gratuita, estava jungido ao fenômeno da nacionalização, que requeria uma espécie de devoção fundada num modo de crença, por sua vez, requeria especialistas versados em seus assuntos. Como em todo processo de especialização, este tende à profissionalização que, em seus esforços, procura depurar o campo científico que se quer especializar de outras influências que não internas ao próprio ramo novo de especialização. (ANDRADE, 2014, p. 253)

Por outro lado, é necessário a presença dos pais para com os seus descendentes, formando um seio familiar bastante próspero para aqueles que futuramente serão capazes de levar adiante a educação passada de pai para filho. É neste cenário, que observamos muitos documentos, como Familiaris Consortio (O Papel da Família Cristã no Mundo Moderno), publicada em 1981. Conforme afirma Clark (2016, p. 134), trata-se do "mais importante documento moderno dirigido às famílias homeschoolers". Nela, podemos encontrar uma afirmação realizada pelo Papa João Paulo II sobre o direito-dever da família, que consiste:

[...] O direito-dever educativo dos pais qualifica-se como essencial, ligado como está à transmissão da vida humana; como original e primário, em relação ao dever de educar dos outros, pela unicidade da relação de amor que subsiste entre pais e filhos; como insubstituível e inalienável, e portanto, não delegável totalmente a outros ou por outros usurpável. (CLARK, 2016, p. 135)

Através desta citação, que foi realizada em 1981, se mostra bastante atual com as dificuldades que os pais encontram na educação dos filhos e o estabelecimento de confiança de encontrar uma escola capaz de assentar uma educação condizente no que diz respeito a modernidade; e mostrando-se respeitosa com o que pais analisam de aprendizado para com os seus pupilos, no ambiente domiciliar.

Foi com este propósito, de "direito-dever" dos genitores, é que foi fundamental a realização de uma entrevista, para obter uma visão extensiva de como ocorre este método educacional, que já 
demonstra ser uma realidade em nosso ordenamento jurídico, pela quantidade de casos e de Projetos de Leis apresentados.

De início, quando perguntada sobre os motivos que levaram os pais a ensinar os filhos em casa, o pai fixou motivos essenciais para a escolha da prática do homeschooling, são eles:

- $\quad$ Acreditamos que podemos oferecer uma educação acadêmica (técnica) melhor do que a atual oferecida pelo Estado;

- Desejamos um processo educacional que respeite o máximo a criança e suas particularidades;

- Concordamos que é um direito e dever Grave de nós pais, oferecermos educação moral e acadêmica aos filhos;

- Somos admiradores da educação Clássica e desejamos que as crianças possam ter acesso a um currículo com este viés;

- Não estamos satisfeitos com a educação oferecida pelo Sistema Público;

- Ficamos preocupados com o alto índice do analfabetismo funcional do nosso País;

- Infelizmente nos últimos exames do PISA (Programa Internacional de Avaliação de Alunos), nosso País sempre ocupa as piores posições. (CUNHA, 2019)

Quando questionado de que forma os filhos estudam, no que tange a rotina e quem ensina os conteúdos, o pai informou que:

[...] A mãe é a maior responsável pela educação, porém o pai participa efetivamente do processo. Nós temos um planejamento anual onde preparamos de acordo com a faixa etária o que vamos ensinar para as crianças, baseado nisso planejamos um cronograma semanal para cada criança. Para que o cronograma aconteça é de fundamental importância a rotina, que procuramos seguir de maneira efetiva e constante. (CUNHA, 2019)

Tendo em vista a estas respostas iniciais, vemos que há similaridade entre as famílias homeschoolers, no que consiste aos motivos levados a prática desse modelo educacional e a rotina que flui perante o dia a dia do domicílio familiar. Ademais, isso demonstra que a família entrevistada segue as famílias citadas por Barbosa (2013), em sua tese de doutorado, que praticam o homeschooling e mostra está familiarizada com os documentos, aportes legais e a utilização de materiais pedagógicos. Destarte, como exemplo e já citado anteriormente, temos a família Vilhena Coelho de Goiás que se caracterizou como sendo a primeira família praticante do ensino domiciliar a possuir procedimento jurídico no ordenamento brasileiro.

Seguidamente, quando perguntada se a família recebe algum auxílio legal, a mãe declara que "somos associados a ANED (Associação Nacional de Educação Domiciliar) que nos disponibiliza um "certo" apoio jurídico [...]" (CUNHA, 2019). Como já analisado, na primeira seção desta pesquisa, a ANED compreende uma associação voltada para a defesa do homeschooling no Brasil e de promover juridicamente a regularização deste instituto, por meio de audiências públicas em que ocorre a participação de famílias - juntamente com os seus filhos - e políticos engajados em instituí-lo no ordenamento brasileiro.

Sob outra perspectiva, é necessário fazer menção sobre a socialização em virtude de suas inúmeras abordagens por parte dos educadores quando se usa o modelo de ensino em análise. Segundo Clark, em pesquisas realizadas para a obtenção de uma resposta correta do que vem a ser a socialização, ela obteve e fez a análise que:

\footnotetext{
No dicionário Webster de 1989, a palavra "socialização" é definida como "socializar ou ser socializado". Socializar significa "ser ativo em afazeres sociais". Provavelmente, os educadores querem dizer que as crianças devem ser capazes de relacionar-se com ou ajustar-se aos demais, em geral colegas da mesma idade, em diversas situações sociais. (CLARK, 2016, p. 391)
}

À vista disso, entramos em um ponto primordial da pesquisa, pois é a partir da socialização onde há uma crítica prolongada para a prática do homeschooling. Para entender essa crítica, é necessário um desenvolvimento de caráter eficaz para aqueles que defendem esse posicionamento. Assim, essa é a questão mais frequente gerando uma preocupação para todos no campo da educação.

Para tal questionamento, Costa faz uma abordagem crítica contra o Projeto de Lei no 3.179/12 do Deputado Federal Lincoln Portela (PR/MG) e elabora teses que defende ser necessárias para o não prosseguimento desta normatização. Contudo, ele cita também como se baseia o homeschooling e que seu 
método educacional privilegia um ensinamento direcionado para aplicação por parte dos pais com os seus aprendizes. Nisso consiste a argumentação de Costa, dentre outros, aduz sobre a representatividade deste projeto:

Por ser representativa [...], transcrevemos a argumentação completa, in verbis:

a) impede o exercício do direito à convivência escolar, uma vez que não oportuniza o direito do filho ir à escola, uma vez que o ensino técnico é oferecido em casa;

b) retira-lhes a oportunidade de conhecer outras concepções de mundo distintas daquelas preconizadas pelos próprios genitores, tendo em vista que o conteúdo a ser trabalhado pelos professores será previamente definido a partir dos valores morais e concepções religiosas do próprio núcleo familiar;

c) restringe o direito à dialogicidade, pois a criança e adolescente está limitado a dialogar apenas com os pares escolhidos previamente pelos seus genitores, impedindo-se a pluralidade de idéias; [...]

f) os filhos de casais não desfrutarão do direito de vivenciar experiências diversas, múltiplas, plurais e inesperadas no ambiente escolar. Perderão a oportunidade de serem surpreendidos, uma vez todo conteúdo e formação no âmbito da educação domiciliar é definido arbitrariamente pelos genitores. Torna-se implementar o ensino democrático; [...] (COSTA apud ALEXANDRE, 2016, p. 12-13)

De outro ponto de vista, quando perguntados de como avaliam as dificuldades e êxitos nessa escolha; e de que maneira respondem às frequentes críticas quanto à falta de socialização proporcionada pelo ensino em casa, a mãe constata que:

\footnotetext{
- As dificuldades são muitas, mas são os nossos filhos e por eles e para eles queremos o melhor, e fazemos tudo. Essa situação jurídica é péssima, faz parecer para a sociedade que fazemos algo de errado, quando não fazemos [...]. Percebe de certa forma um preconceito das pessoas no que diz respeito a educação domiciliar.

- Acreditamos que a verdadeira socialização ocorre primeiro em casa, onde a criança cercada de um ambiente favorável e segura, cria vínculos, laços com os irmãos, pais, avós, primos que a deixam segura e pronto para "socializar" em qualquer lugar, não só na escola pois existem crianças e gente em outros lugares além da escola, como aulas extracurriculares, esportes, parquinhos e outros. (CUNHA, 2019)
}

Através do exposto, nota-se que há divergências bastante pertinentes quanto a socialização para com a criança que enfrenta as dificuldades em desenvolver experiências tanto no ambiente escolar quanto no ambiente domiciliar. Existem casos onde crianças não conseguem se adaptar a vida escolar (rotina, professores, método de ensino e os colegas de classes) e os pais procuram realizar um ensino doméstico de acordo com as necessidades de seus filhos.

Outros casos, em que os filhos possuem alguma deficiência física e/ou motora e os pais escolhem a educação em casa. E por fim, há a existência de pais, como vimos através do questionário aplicado a família Cunha, que preferem que seus filhos sejam educados em casa e estejam mais perto dos pais, irmãos, avós e primos; e como relata a mãe "acreditamos que uma educação total é uma educação que chega ao coração da criança e que a faz ter fascínio e admiração pelo Saber, e ninguém pode chegar mais fácil ao coração de uma criança como os pais" (CUNHA, 2019).

Portanto, é neste sentido que os educadores precisam se aprofundar naquilo que é mais eficaz ao aprendizado de todas as crianças em seus diferentes ambientes de ensino e suas maneiras de serem aprendizes com o que é ensinado. Porém, é necessário haver uma legalidade perante ao ensino do homeschooling e sua regularização em território brasileiro, não para agradar somente os adeptos, mas para explorar as diversas possibilidades que pode trazer esta temática aos pais e filhos, e ocasionar uma escolha pertinente perante o ordenamento jurídico.

Por fim, o próprio sistema educacional poderia propiciar uma formação mais dinâmica para os educadores. Com isso, a finalidade é de conceber de maneira mais eficaz as particularidades de cada educando e identificando o tempo de desenvolvimento, de cada um deles; sobretudo, compreender que o ambiente familiar em detrimento do ambiente escolar poderá proporcionar condições mais adequadas a cada caso.

\section{CONSIDERAÇÕES FINAIS}


Resta evidente a grandeza que é a educação e a necessidade que há em torná-la abrangente para todos os cidadãos, conforme o texto constitucional. É nesse contexto atual de nosso país onde encontramos a necessidade de analisar outros métodos educacionais presentes no meio da população brasileira e que advém de outros países mais equipados nos moldes educacionais. Tendo em vista que o governo atual sinaliza com novas ideias mediante a educação brasileira, sendo elas desde a préalfabetização até os projetos de pesquisas decorrentes do meio acadêmico, presenciamos um momento oportuno de abranger novas ideias e outras não tão novas assim, como é o caso do homeschooling, para as famílias que queiram desenvolver e educar os seus filhos; e para as escolas buscarem fortalecer seus métodos de aprendizagem

O objetivo da pesquisa realizada visa compreender a situação jurídica do homeschooling em nosso ordenamento e conhecer os motivos pelo qual não há uma legalidade para a prática deste método educacional em nosso país. Porém, pelo fato de não haver uma legislação que especifique a prática, não há em nosso ordenamento uma proibição para a sua utilização por parte das famílias que queiram aplicar, pois a Constituição Federal e a Declaração Universal dos Direitos Humanos abrem possibilidades para que os próprios pais escolham o gênero de instrução utilizado para prover a educação de seus descendentes e a caracteriza como um dever.

Constatou-se ainda a existência de muitas dificuldades para a prática do ensino domiciliar em nosso país, pois encontra um certo preconceito para aqueles que buscam realizar a educação domiciliar. Muitas famílias, inclusive a do questionário objeto da análise, convivem como se estivessem realizando uma prática anormal e que vai contra a legislação brasileira. É por esses motivos que muitos pais desistem de adotá-lo e decidem submeter os filhos ao Estado, pois mesmo as famílias com condições de colocar as crianças em escolas particulares não possuem a capacidade de colocar em prática as suas percepções perante as escolas.

Verificou-se também que a socialização faz parte de todo o desenvolvimento presente na vida de cada indivíduo, sobretudo no que indica a capacidade de se adaptar em um mundo repleto de características e difusões de ideias. Assim, muitos educadores defendem a concepção de que é na escola o local mais adequado para o desenvolvimento da socialização, ou seja, um ambiente totalmente propício para haja uma pluralidade de culturas. Nessa situação, a criança terá um leque de opções para se adequar a todos eles.

Notadamente, o estudo sobre o homeschooling caracteriza-se pelo fato de os pais buscarem para os filhos a capacidade deles se socializarem, embora defendam que é na família o primeiro local de socialização para as crianças e não na escola. Nesse ambiente escolar, ao invés de unir os alunos, observamos que há distinções no qual cada aluno é obrigado a se colocar diante de um grupo em que ele se sinta melhor. Além do mais, as diversas formas de bullying, por meio de apelidos, de agressões e de abusos; gera para o aluno uma maneira de rejeitar aquilo que não condiz com que os pais ensinam em casa e, desse jeito, a escola não tem como controlar.

Através das pesquisas realizadas, compreende-se que o homeschooling não é de aplicação para todos e nem que este método de ensino é contrário as escolas e aos professores. De outro modo, as famílias defendem que é necessário a existências das escolas e a continuação dos professores; e que esses são essenciais, pois os próprios pais homeschoolers são os próprios professores de seus filhos e levam adiante o estudo em casa. O que as famílias homeschoolers almejam é que os pais tenham a plena capacidade de escolha na forma de ensino que querem para os filhos e se sintam capazes de propagar os seus métodos que obteve por meio de materiais pedagógicos como: apostilhas, livros e cursos que são encontrados na internet como forma de auxílio. Além disso, existem presença de institutos, como o Instituto Cidade de Deus, que são formados por professores que produzem materiais desde a idade de 3 (três) anos até 16 (dezesseis) anos, quando da conclusão do Ensino Médio; e a ANED, que produzem materiais e realiza a defesa dessas famílias.

Portanto, para que haja a permanência desse método educacional é necessário à sua abrangência perante o ordenamento jurídico. Os inúmeros casos perante o Poder Judiciário e o próprio julgamento recente no STF, na data de 12/09/18, em regime de repercussão geral, Recurso Extraordinário $\mathrm{n}^{\circ}$ $888.815 / \mathrm{RS}$, se manifestou improcedente pelo ensino domiciliar, somente pelo fato de ausência de norma legal que regulamente a prática do homeschooling. Sendo assim, urge a necessidade de regulamentação desse instituto e que seja viabilizado a milhares de famílias, em solo brasileiro, para dar continuidade a esta prática que se mostra eficaz ao futuro da educação.

\section{REFERÊNCIAS}


AGUIAR, Alexandre Magno Fernandes Moreira. A situação jurídica do Ensino Domiciliar no Brasil. Disponível em: https://www.aned.org.br/sobre-nos/quem-somos-aned , Acesso em 12/09/19 às 17h37min.

ALEXANDRE, Manoel Morais de O. Neto. Quem tem medo do homeschooling? o fenômeno no Brasil e no mundo. Brasília: Câmara do Deputados, Consultoria Legislativa, 2016. 22p. Disponível em: bd.camara.gov.br/bd/handle/bdcamara/30982, Acesso em: 30/09/19 às 09h24min.

ANDRADE, Édison Prado de. A Educação Familiar Desescolarizada como um Direito da Criança e do Adolescente: relevância, limites e possibilidades na ampliação do Direito à Educação. 2014, 552. Tese (Doutorado) - Faculdade de Educação, Universidade de São Paulo, São Paulo, 2014. Disponível em: www.teses.usp.br/teses/disponiveis/48/48134/tde-10112014-111617/ptbr.php, Acesso em: 19/05/19 às 20:00 horas.

BARBOSA Luciane Muniz R. Ensino em casa no Brasil: um desafio à escola? 2013.348 f. Tese (Doutorado) - Faculdade de Educação, Universidade de São Paulo, São Paulo, 2013. Disponível em: www.fcc.org.br/fcc/images/pesquisa/premio_capes/pdf/LUCIANE_MUNIZ_RIBEIRO_BARBOSA_rev. pdf, Acesso em: 22/05/19 às 21:00 horas.

BRASIL. Constituição da República Federativa do Brasil - 1988. Disponível em: www.planalto.gov.br/ccivil03/constituicao/constituicao.htm, Acesso em: 20/05/19 às 23h30min.

BRASIL. Declaração Universal dos Direitos Humanos. Disponível em: https://nacoesunidas.org/wpcontent/uploads/2018/10/DUDH.pdf, Acesso em: 18/11/19 às 11h45min.

BRASIL. Lei n. 9.394, de 20 de dezembro de 1996. Fixa diretrizes e bases da educação nacional. Disponível em: www.planalto.gov.br/ccivil03/leis/19394.htm, Acesso em: 20/05/19 às 23h10min.

BRASIL. Projeto de lei $n^{\circ} 3.179$, de 08 de fevereiro de 2012. Acrescenta parágrafo ao art. 23 da Lei $\mathbf{n}^{\circ}$ 9.394, de 1996, de diretrizes e bases da educação nacional, para dispor sobre a possibilidade de oferta domiciliar da educação básica. Disponível em: https://www.camara.leg.br/proposicoesWeb/prop_mostrarintegra;jsessionid=8DDB857E73A548D57F6A 2E6C383ACC8E.proposicoesWebExterno2? codteor=963755\&filename=PL+3179/2012, Acesso em: 29/11/19 às 17:00 horas.

BRASIL. Projeto de lei $\mathrm{n}^{\circ} 2.401$, de 17 de abril de 2019. Dispõe sobre o exercício do direito à educação domiciliar, altera a Lei no 8.069, de 13 de julho de 1990 - Estatuto da Criança e do Adolescente, e a Lei $\mathbf{n}^{0}$ 9.394, de 20 de dezembro de 1996, que estabelece as diretrizes e bases da educação nacional. Disponível

em: https://www.camara.leg.br/proposicoesWeb/prop_mostrarintegra?codteor=1734553\&filename=PL+2401/ 2019, Acesso em: 27/11/19 às 18:00 horas.

CLARK, Mary Kay. Homeschooling Católico: um guia para os pais. Tradução de Lorena Cutlak, edição de Renan Santos, - Porto Alegre, RS: Concreta, 2016.

CUNHA, Cleylton Paixão da. Entrevista concedida a André Felipe Vilanova Costa. Caxias, 24 de outubro de 2019. [A entrevista encontra-se transcrita no Apêndice "B" deste artigo científico].

CUNHA, Daniele Dandara Mota Teixeira. Entrevista concedida a André Felipe Vilanova Costa. Caxias, 24 de outubro de 2019. [A entrevista encontra-se transcrita no Apêndice "B" deste artigo científico].

FRANCIULLI NETTO, Domingos. Aspectos constitucionais e infraconstitucionais do ensino fundamental em casa pela família. Biblioteca Digital Jurídica, STJ, 2005. Disponível em: ww2.stj.jus.br/publicacaoinstitucional/index.php/coletânea/article/view/1703/1627, Acesso em: 07/10/19 às $16 \mathrm{~h} 06 \mathrm{~min}$.

GAZETA DO POVO. Homeschooling deve ser aprovado até dezembro, diz Damares. Brasília: Leonardo Desideri. Disponível em: https://www.gazetadopovo.com.br/educacao/homeschooling-deveser-aprovado-no-brasil-ate-novembro-diz-damares/, Acesso em: 08/10/19 às 11h:33min. 
JOAO PAULO II. Exortação Apostólica Familiaris Consortio. 1981. Disponível em: http://www.vatican.va/content/john-paul-ii/pt/apost_exhortations/documents/hf_jpii_exh 19811122_familiaris-consortio.html, Acesso em: 08/11/19 às 15h45min.

MARTINEZ, Flávia Wegrzyn. Bullying no ambiente escolar: a importância de intervir. 2011. Monografia (Especialização em Saúde para Professores do Ensino Fundamental e Médio) - Universidade Federal do Paraná Disponível em: acervodigital.ufpr.br/bitstream/handle/1884/35437/FLAVIA\%20WEGRZYN\%20MARTINEZ.pdf?seque nce=1\&isAllowed=y, Acesso em: 12/09/19 às 15:00 horas.

PAULO VI. Declaração Gravissimum Educationis Sobre a Educação Cristã. 1965. Disponível em: http://www.vatican.va/archive/hist_councils/ii_vatican_council/documents/vatii_decl_19651028_gravissimum-educationis_po.html, Acesso em: 11/10/19 às 16h53min.

ROCHA, Ronai. Quando ninguém educa: questionando Paulo Freire. São Paulo: Contexto, 2017.

Informações sobre os autores:

AFBC: Graduando do $10^{\circ}$ Período do Curso de Bacharelado em Direito. E-mail: andrevilanova@hotmail.com.

MSM: Professora Orientadora. Doutoranda pelo Programa de Pós-Graduação em História da Universidade do Vale do Rio dos Sinos - PPGH/UNISINOS. Mestra pelo Programa de Pós-Graduação em História, Ensino e Narrativas da Universidade Estadual do Maranhão - PPGHEN/UEMA. Atualmente é Professora Titular do Curso de Bacharelado em Direito da Faculdade do Vale do Itapecuru - FAI, Advogada atuante na Comarca de Caxias-MA e Coordenadora do Núcleo de Prática Jurídica da Faculdade do Vale do Itapecuru - NPJ/FAI. E-mail: profmeiriele@ gmail.com.

Contribuição dos autores: AFBC: conceitualização, captação de recursos, supervisão, redação. 